\title{
A case study on the quality of healthcare in Uganda: Examining the effectiveness, safety, patient-centred and timeliness of district healthcare facilities
}

\author{
David Mwesigwa $^{*}$, Khalid Abdul Wahid ${ }^{2}$, Nipon Sohheng ${ }^{3}$ \\ Department of Public Administration and Management, Faculty of Management Sciences, Lira \\ University, Lira, Uganda ${ }^{1^{*}}$ \\ Faculty of Information Management, Universiti Teknologi MARA Kelantan Branch, Kelantan, \\ Malaysia $^{2}$ \\ Faculty of Political Sciences, Ramkhamheang University, Bangkok, Thailand ${ }^{3}$ \\ mwesigwadavid22@gmail.com $^{l^{*}}$, awkhalid@uitm.edu.my ${ }^{2}$, musa1234@yahoo.com ${ }^{3}$
}

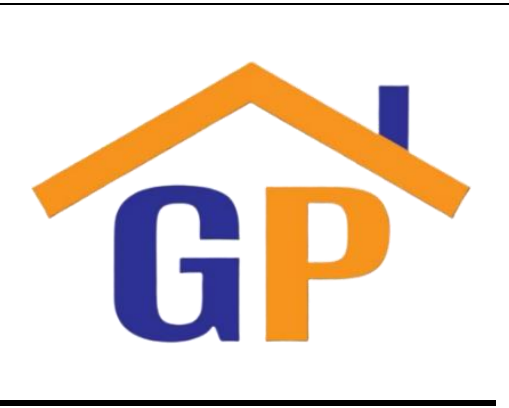

Article History

Received on 2 July 2021

Revised on 15 July 2021

Accepted on 2 August 2021

\begin{abstract}
Purpose: This study aims to examine the quality of healthcare in Uganda in terms of effectiveness, safety, patient-centred and timeliness of District Healthcare Facilities.
\end{abstract}

Research methodology: This study took a case study design involving an intensive, descriptive, and holistic analysis of PHFs in the Hoima district. Case study research involves studying a single entity in depth so as to understand the larger cases; to describe and explain rather than predict.

Results: The main factors affecting the quality of healthcare were; National health system, overall working environment, national budgetary allocation to the health sector, and collaboration between health centres and hospitals. Enhancing the quality of healthcare requires addressing the aforesaid as well as engaging with the LLGAs.

Limitations: This study only covers one district local government in a country where there are over 100 districts hence limiting the notion of generalization of results.

Contribution: This study contributes to understanding healthrelated issues from the perspective of quality, which is very key in health service delivery.

Keywords: Healthcare, Effectiveness, Safety, Patientcenteredness, Timeliness

How to cite: Mwesigwa, D., Wahid, K, A., \& Sohheng, N. (2021). A case study on the quality of healthcare in Uganda: Examining the effectiveness, safety, patient-centred and timeliness of district healthcare facilities. Journal of Governance and Accountability Studies, 1(2), 133-144

\section{Introduction}

There is a level of a muddle over the notion of quality healthcare. It is used in a variety of circumstances with diverse connotations, and if not cautious, the meaning may lack clearness as a working idea. For example, some academics identify the availability of adequate physical infrastructures, personnel and medical supplies as quality healthcare. Such insight has been critiqued for being very trivial. Quality healthcare delivery encompasses the various infrastructures, personnel, equipment, transportation and medicines that are aptly put to proper use for the benefit of every patient without any discrimination (Ronca et al., 2020). It embraces the potential of a health facility to reduce, as much as possible, the fatality rate arising out of preventable causes as well as guaranteeing that any form of deferrals in delivering a service is alleviated; this is what $\mathrm{Mu}$ et al. (2019) call service inventiveness and administrative regeneration. This presupposes that quality healthcare can and essentially translates into better health and, to a number of people, quality healthcare is the same as receiving sufficient medical attention whenever it is sought, by patients and or clients, at a health facility (Okpala, 2020). 
In the case of Uganda, quality healthcare is proportionate to the structure of healthcare and or healthcare facilities in the country. We focus our attention on the healthcare structure at the local government level. The lowest health facility is health centre II positioned at the parish level of local administration, which does not handle any medical examination save for giving out available but basic drugs for simple illnesses such as malaria to clients within its vicinity. While this is so for Uganda, the findings of a study conducted by Thuy et al. (2020) reveal similar conditions mainly manifesting through a meagre availability of vital medications throughout every level of primary healthcare in Vietnam. The quality of healthcare at that facility (health centre II) is mainly described in terms of the availability of basic medical supplies and the requisite personnel who are both ready and willing to offer primary attention. The facility does not operate on weekends; neither operates outside the official working time of 08.00 to 17.00 hours. Also, the facility is run by very few healthcare personnel who have only acquired and been registered as enrolled nurses/midwives or a health-related diploma. The second level is health centre III positioned at the sub-county level of local government. Unlike health centre II, this level handles deliveries, maternal and child health, general medicine, treatment, minor operations, antiretroviral treatment (ART) services, reproductive healthcare services, among many others (Jillian \& Kizito, 2020). And the facility has a number of personnel, including a medical assistant and a senior nursing officer who is charged with the supervision of subordinate personnel at the facility. The facility works day and night since it operates a multi-purpose patient ward. Consequently, the quality of healthcare at health centre IIIs is measured along with a wider scope compared to the first level.

The third level is the health sub-district positioned at the county level of local administration. It is responsible for all referral cases arising or emerging from the health centre IIIs within its jurisdiction. Consequently, the health sub-district is expected to handle a number of referral cases from the immediate lower level and, likewise, to refer every case that requires more specialised attention to the district hospital. The health sub-district is followed by the district hospital, which covers several cases referred to it from the subordinate facility (the health sub-district) as well as making any necessary referrals to the regional referral hospital. Ideally, every district in Uganda is expected to have a district hospital; however, due to Gerrymandering, which has seen new districts being formed without clear budget lines, this vision is yet to be achieved. Therefore, this study focuses on health centre IIIs and health centre IIs, given that the two falls within the jurisdiction of LLGAs. Accordingly, both health centre II and health centre III are overseen by a health management committee (HMC) usually appointed by the sub-county council. The membership of the HMC does not have to be professionals. In reality, many HMC members are selected from the adjacent community as long as such members are both willing and can serve their community. In a number of rural sub-counties in Uganda, the HMC membership is largely composed of the illiterate and the semi-illiterate. As a consequence, the HMC is charged with ensuring that quality health care at a respective PHF is taken care of on behalf of the subcounty council.

\section{Literature review}

\subsection{The concept of quality healthcare}

According to O'Donovan et al. (2020), quality healthcare means that a relevant health facility is able to dispense its obligations using every available resource ranging from physical infrastructure to personnel for the satisfaction of clients who visit the facility. Thus, quality health care means more than just physical and personnel resources. However, several researchers have described quality healthcare from a more general view, though in different settings; Okpala, (2020) understands quality healthcare in terms of shared leadership between the various departments and or units within the facility. The WHO (2016) proposes a framework for enhancing the quality of healthcare. This model summarises quality healthcare as four interrelated dimensions, namely; effectiveness, safety, patient-centred, and timeliness; these four dimensions form the basis of this study.

Another definition offered by Richter and Kazley (2020) perceives quality healthcare as a set of preconditions for operating a health facility that makes a patient/client more likely to choose to come back to the facility in which they receive satisfactory services. This view is from the fact that a 
patient/client might be served with every competence deserved but goes minus being satisfied. Others have described quality healthcare to mean that every stakeholder can recognise and continually seek to fill the existent gap/s that make them more likely to discover and generate more meaningful healthcare for the community (Imlawi \& Gregg, 2020). The constant seeking appears to put prominence on the fact that quality healthcare is never a done deal but a continuous process. It is manifest from the preceding that the concept of quality healthcare rises above the obtainability of both physical and nonphysical facilities; it also suggests the utilisation of those facilities in delivering satisfactory healthcare services as well as the bond between the patient and the healthcare provider. In this study, quality healthcare is demarcated as the deployment of available material and non-material resources as well as social care afforded to a patient at a healthcare facility. It is construed then that quality healthcare entails of physical infrastructures, skilled personnel, medical equipment, and supplies that facilitate the patient to receive the necessary service in which they can be fulfilled not only in the facility but after recovery as well. In their study, Jayantkumar and Dasharathbhai (2019) note that the duty of the LLGAs is to work, in close collaboration with the HMC as well as a well-functioning team of skilled personnel, towards ensuring that the desired service is delivered to the patient and or client right from the time they enter the gates of a healthcare facility up to the time they are discharged. The aforesaid description gives a deep-rooted picture of what ought to be quality public health.

\subsection{Health promotion and disease prevention}

The magnitude to which a healthcare facility is able to provide quality healthcare, which meets the growing healthcare needs in the current and future epoch, is appealing to a number of researchers and policy analysts internationally and locally. This concern buds from two key issues. The first is that there are indications that the patterns of disease are shifting swiftly with new infectious diseases evolving. An unprecedented demographic explosion and dynamic human actions are triggering the health sector to evolve substantial restructurings (Gomez-Delgado et al., 2020). Infectious diseases such as Ebola, nodding, and very recently COVID-19 that have claimed hundreds of thousands of human lives on a global scale cannot be taken too lightly. COVID-19, for example, has impacted and continues to impact every aspect of human life, ranging from socio-economic, political, to institutional. Socially, global institutions and governments have been forced to adopt what is known as social distancing, virtual education system, digital worship, and all manner of social activities such as sports, tourism, and leisure put to a halt as a precautionary measure (Simmons, 2020; Fairchild, Gostin \& Bayer, 2020; Rahman, 2020; Wasdani \& Prasad, 2020). This has had an enormous impact on the social structure of human society in a number of ways. For example, in the United Kingdom, the elderly and poorer people turned out to be less liable to work from their habitual home, persons identified with psychological health syndrome displayed less trust in government, more obligatory purchasing, and persons diagnosed with COVID-19 signs required to exercise self-isolation for extended periods (Jaspal et al., 2020). On the economic side, a colossal number of economic activities have suffered countless losses, with a number of them closing down, and nations are grappling with the huge debt burden resulting from the need to lessen the budget deficit as a result of countless economic activities running out of operation as well as the need to meet the growing needs of the unemployed population.

Politically, governments have been forced, by the international community, to adopt new modus operand necessary in such critical times, for example, regulated political campaigns and other political activities as well as adopting standard operating procedures (SOPs) when attending key meetings of both cabinet and Parliaments (Morgan, 2020; Jaja et al., 2020). A number of institutions, mainly education, underwent a full year of closure, resulting in unavoidable school dropouts and near-collapse of the total education system. Universities and other tertiary institutions, on the other hand, were required to adopt what is called open distance and electronic learning (ODeL) so that the actual physical number of learners meeting with the facilitators through face-to-face sessions is reduced as much as possible while delivering the teaching and learning (Xie, Siau \& Nah, 2020; Suleri, 2020; Varea \& Gonzalez-Calvo, 2020; Assaf, 2020). The consequence of this adjustment is that it is no longer adequate for healthcare facilities to have the physical infrastructures (such as buildings), personnel (doctors, nurses, and support staff), and medical supplies (including medical equipment, medicine, and other assorted items) only but they must have the ability to deliver an excellent, safe, and prudent set of services. 
The second concern is that the present healthcare facilities are not offering patients the kind of expert attention that is needed to be healthy and happy as they move out of the facility (Cai et al., 2020). Health centres have been condemned for the fact that their method of delivering healthcare has very little significance to the physio-emotional requirements of their clients as a result of deteriorating quality (Leonce, 2020), which accordingly forces a good number of patients to abandon public health facilities (PHFs) for private health facilities. For example, a study by Kwateng et al. (2019) conducted in Ghana reveals a higher level of attention and responsiveness at private healthcare facilities than the public. The picture does not appear to be different for Uganda, and suggestions from previous studies indicate that the high percentage of private health facilities is not only a result of structural adjustment programs (SAPs) but likewise due to a dearth of quality healthcare that patients are looking for (O'Donovan et al. 2020). Anecdotal evidence in support of this assertion shows that out of every ten patients in Uganda, approximately six of them have no confidence in receiving a preferred service and are not enthusiastic about visiting any PHF. That is possibly why a study conducted by Bahendeka et al 2019) underlined the need for arranging healthcare systems along with the 'extended attention model' and reinforced by web-based automated registers as a strategy for improved quality of healthcare in Uganda.

According to Walcott et al. (2020), a number of patients who try to find treatment in PHFs have to tolerate a considerable economic burden, and for those who receive gratifying healthcare in PHFs notwithstanding the whole lot, they select the perceived private wing (within the PHF and continue raising serious concerns about the quality of service offered). Likewise, a study conducted by Abiodun and Adeyemi (2020) covering 29 PHFs exposed a general quality gap of $51.7 \%$, with serious shortages in methodical competence. The results of this study were in agreement with those of comparable studies, for example, Omona and Namuli (2020). Therefore, as exposed in these studies, the magnitude of quality maintained the fact that a number of PHFs are not adequately facilitated.

The notion of quality health care is puzzling to the conventional idea of healthcare and attracts queries regarding the significance of PHFs at the different levels. Generally, it is the hope of patients to receive quality healthcare every time they visit a PHF. According to Essue and Kapiriri (2020), this hope is sensible from the view of 'health system priority setting,' which explains that the key drivers of demand for PHFs are the prospect of quality healthcare. However, with the present-day challenges where visiting a PHF is professed as a 'last resort, this hope is a sheer deception for several patients and the community in general. In consideration of the quality of healthcare delivered by a number of PHFs in Uganda, as previously deliberated, this paper suggests a direct involvement of lower local government authorities (LLGAs). Whereas scholars such as Morais De Sousa et al. (2020) have put forward approaches in the framework of their own setting (such as greater financial autonomy), not any of these approaches appear absolutely suitable for the Ugandan circumstances where the situations of healthcare delivery are pretty diverse. In Uganda, obtainable studies (such as Wright, 2020) on healthcare are scarce, and they typically put emphasis on disease prevalence, epidemiology, and biostatistics and offer recommendations. They do not put forth clear means in which the quality of healthcare can be enhanced by LLGAs.

\section{Statement of the problem}

The key emphasis of this study is the dominant status quo of low quality of healthcare in PHFs in Uganda, which is a central causative to patient flight from PHFs to private health facilities in the country. There are signs that the quality of healthcare experience in Uganda is organisational. That is, a number of PHFs are incapable of delivering quality healthcare for the dearth of vital supplies, and they are, as a consequence, left choiceless. This status quo is a huge trial for the significance of PHFs, and hence, desires instant consideration. Resulting from this challenge, this study probes the quality of healthcare in PHFs so as to determine means of enhancement.

\section{Objectives of the study}

The purpose of this paper was to analyse the quality of healthcare in PHFs in the Hoima district. In achieving this purpose, the following objectives were prioritised: (a) to determine the quality of healthcare among PHFs in Hoima district; (b) to determine the factors affecting the quality of healthcare 
in PHFs in Hoima district; (c) to determine means to enhancing the quality of healthcare in PHFs; And (d) to establish the strategies which LLGAs adopt to enhance the quality of healthcare in PHFs in Hoima district.

\section{Research methodology}

This study took a case study design. This design involved an intensive, descriptive, and holistic analysis of a single entity. In this case, the entity was presumed to be PHFs in the Hoima district. It further involved studying a single entity (that is, Hoima district) in-depth so as to understand the larger cases of, for instance, mid-western Uganda; to describe and explain rather than predict the quality as well as healthcare delivery. This design is good for smaller samples using in-depth analysis, seeing that it is convenient when little is known about an issue such as the quality of healthcare in a particular locale. Respondents were thus selected using simple random sampling. The sample consisted of respondents, including health management committee members, healthcare workers, and local leaders selected from the target population. The sample of 110 subjects was distributed among eight healthcare facilities as follows: Butema (20), Mparangasi (18), Bulindi (20), Dwoli (17), Kabaale (18) and Tonya (17). Data were collected using a researcher-designed self-administered questionnaire that was administered to all the sampled respondents though $102(85 \%)$ responded. A questionnaire was justified because all the respondents were literate and could read well and respond to the items on the tool. The questionnaire was structured in line with the objectives of the study, and every protocol, including ethical clearance and obtaining permission, was adhered to before and during data collection.

\section{Data quality control}

Content validity was established by calculating the content validity index (CVI) of all items. As a rule of thumb, CVI at 0.70 and above is acceptable. As a consequence, the CVI yielded an average 0.735 . The instrument was pilot tested by administering the questionnaire to 10 respondents. Basing on the results, the Cronbach's Alpha Coefficient was used to test for reliability. Since Cronbach's alpha is a test reliability technique that requires only a single test administration to provide a unique estimate of the reliability for a given test (Gliem and Gliem, 2003), the result of 0.814 was deemed reliable.

\section{Data presentation and analysis}

All primary data were edited for completeness and consistency to ensure that the respondent's responses do not have errors. It was analyzed using both descriptive statistics and inferential statistics. The variables were; the quality of healthcare, factors affecting the quality of healthcare, enhancing the quality of healthcare, and the strategies for LLGAs to adopt to enhance healthcare quality in PHFs. In order to measure the variables, the study used a five-point Likert scale with items ranging from 1-5, where; $1=$ strongly disagree, $2=$ Disagree, $3=$ Not sure, $4=$ Agree, $5=$ strongly agree.

\section{Results and discussion}

The results of this study are presented within the framework of the four objectives, viz.: the quality of healthcare among PHFs; factors affecting the quality of healthcare in PHFs; means by which the quality of healthcare in PHFs can be enhanced; and the strategies which LLGAs adopt to enhance the quality of healthcare in PHFs. Consequently, this study took descriptive statistics of the mean $(\mu)$ and standard deviation (std. dev.) to describe each of the four dimensions of quality healthcare: effectiveness, safety, patient-centeredness, and timeliness. The scores facilitated interpreting the quality of healthcare in the area of study. To ease the analysis of mean scores pertaining to healthcare quality, the researcher embraced a range of scores. That is, mean scores not more than 2.500 were understood as 'low quality of healthcare,' mean scores ranging between 2.500 and 3.500 were understood as 'moderate quality of healthcare,' mean scores beyond 3.500 were understood as 'high quality of healthcare.' Also, the standard deviations near-zero show consistency in opinions on the quality of healthcare, while standard deviations distant from zero show inconsistency in opinions on the quality of healthcare. 
Table 1. Descriptive statistics on quality of healthcare $[\mathrm{N}=102)$

\begin{tabular}{|c|c|c|c|}
\hline No & Effectiveness & Mean & Std. Dev. \\
\hline 1 & Case-fatality rates for specific diseases & 4.476 & 0.749 \\
\hline 2 & Hospital admission rate & 4.321 & 0.790 \\
\hline 3 & $\begin{array}{l}\text { Percentage of sick child visits which health workers counselled } \\
\text { mother on nutrition }\end{array}$ & 4.330 & 0.817 \\
\hline 4 & $\begin{array}{l}\text { Percentage of women aged } 40 \text { years and over who reported a } \\
\text { mammogram within the past two years }\end{array}$ & 4.234 & 0.846 \\
\hline \multirow[t]{2}{*}{5} & $\begin{array}{l}\text { Percentage of women who received prenatal care in the first } \\
\text { trimester }\end{array}$ & 4.389 & 0.784 \\
\hline & Average & 4.350 & 0.797 \\
\hline \multirow{5}{*}{$\begin{array}{l}1 \\
2 \\
3\end{array}$} & Safety & & \\
\hline & Percentage of providers who know hand hygiene guidelines & 3.844 & 1.098 \\
\hline & Birth trauma rate in neonate per 100 live births & 4.090 & 1.048 \\
\hline & $\begin{array}{l}\text { Percentage of adults whose provider asks about other prescribed } \\
\text { medication }\end{array}$ & 3.993 & 1.152 \\
\hline & Average & 3.976 & 1.099 \\
\hline & Patient-centeredness & & \\
\hline 1 & $\begin{array}{l}\text { Percentage of adults with recent heath visits who stated their } \\
\text { provider always listened to what they had to say, }\end{array}$ & 3.090 & 1.067 \\
\hline 2 & $\begin{array}{l}\text { Percentage of adults with recent health visits who stated their } \\
\text { provider explained things clearly }\end{array}$ & 3.896 & 1.086 \\
\hline \multirow[t]{3}{*}{3} & $\begin{array}{l}\text { Percentage of adults with recent health visits who stated their } \\
\text { provider showed respect to them }\end{array}$ & 3.595 & 1.075 \\
\hline & Average & 3.527 & 1.076 \\
\hline & Timeliness & & \\
\hline 1 & Percentage of persons who state they have a usual source of care & 2.174 & 1.171 \\
\hline 2 & $\begin{array}{l}\text { Percentage of emergency department visits where patients left } \\
\text { without being seen }\end{array}$ & 2.350 & 1.489 \\
\hline \multirow[t]{3}{*}{3} & $\begin{array}{l}\text { For heart attack patients, the median time to thrombolytic therapy } \\
\text { or percutaneous transluminal coronary angioplasty (PTCA) }\end{array}$ & 2.692 & 1.184 \\
\hline & Average & 2.405 & 1.281 \\
\hline & Overall average & $\mathbf{3 . 5 6 5}$ & 1.063 \\
\hline
\end{tabular}

Legend: $\leq 2.500$ (low quality), $2.500-3.500$ (moderate quality), $\geq 3.500$ (high quality)

Source: Primary data.

The first dimension (effectiveness) covers five elements (table 1 above). Results indicate that all the five elements scored above 3.500, suggesting the high quality of healthcare as measured from the five elements with an average score falling in the same region as well $(\mu=4.350 ;$ std. dev. $=0.797)$. The second dimension (safety) covers three elements. The results in table 1 above indicate that while respondents rated birth trauma rate in neonate per 100 live births above the remaining two elements $(\mu=4.090$, std. dev. $=1.048)$, whose mean scores were 3.844 and 3.993 , the overall average was impressive $(\mu=3.976$; std. dev. $=1.099)$. The result suggests that the quality of healthcare in terms of safety is high. The third dimension (patient-centeredness) covers three issues. Based on the results summarised in table 1 above, it is revealed that in terms of the percentage of adults with recent heath visits who stated their provider listened to what they had to say, the results show moderate quality $(\mu=3.090$, std. dev.1.067). While the other two elements scored a mean above 3.500, the element 'percentage of adults with recent health visit who stated their provider showed respect to them' was very close $(\mu=3.595$; std. dev. $=1.075)$ and so is the average score for patient-centeredness $(\mu=3.527$; std. dev.=1.075). And dimension four (timeliness) covers three elements as well. Results indicate that only one of the three elements scored above 2.500 , that is, 'for heart attack patients, the median time to thrombolytic therapy or percutaneous transluminal coronary angioplasty (PTCA)' ( $\mu=2.692$; std. dev. $=1.184$ ). The other two elements scored below 2.500, and so was the average score for timeliness $(\mu=2.405$; std. dev. $=1.281)$, suggesting a low quality of healthcare. Overall, the four dimensions 
(effectiveness, safety, patient-centeredness, and timeliness) generate a mean score of 3.565 and a standard deviation of 1.063. These results indicate a moderate quality of healthcare in the area of study.

\section{Factors affecting the quality of healthcare in PHFs in Hoima district}

Several factors that are unfriendly to the quality of healthcare in the Hoima district have been identified. Using descriptive statistics, each factor was analysed using means and standard deviations, as illustrated in Table 2 below. Descriptive statistics were used to show the degree of the problem in terms of mean and standard deviation. These scores facilitated appreciating the factors affecting the quality of healthcare in PHFs. The scores were rated as follows: means less than or equal to 2.500 were interpreted as 'low degree.' Mean scores ranging between 2.500 and 3.500 were interpreted as 'moderate degree', and mean scores above 3.500 were interpreted as 'high degree.' In addition, the standard deviations not far off zero show consistency of views on the factor/s while standard deviations distant from zero show inconsistency of views on the factor/s.

Table 2. Descriptive statistics on the factors affecting the quality of healthcare in the Hoima district

\begin{tabular}{llrr}
\hline No & Construct & Mean & Std. dev. \\
1 & National health system & 4.366 & 0.739 \\
2 & Overall working environment & 4.230 & 0.933 \\
3 & National budgetary allocation to the health sector & 4.220 & 0.807 \\
4 & Collaboration between health centres and hospitals & 4.017 & 0.855 \\
5 & The link between health workers' and patients' views on quality & 3.754 & 1.331 \\
6 & Community health education & 3.454 & 1.088 \\
7 & Industrial work experience is undertaken by medical trainees & 3.706 & 1.076 \\
8 & Commitment of medical schools and or colleges & 3.512 & 1.223 \\
9 & Demographic dynamics & 3.405 & 1.065 \\
10 & Number of health workers at a facility & 2.502 & 1.174 \\
& Average & $\mathbf{3 . 7 1 7}$ & $\mathbf{1 . 0 2 9}$ \\
\hline
\end{tabular}

Legend: $\leq 2.500$ (low degree), 2.500 - 3.500 (moderate degree), $\geq 3.500$ (high degree)

Source: Primary data.

Ten factors were presented to the respondents. These were generated from a survey conducted at one PHF in the district a week before official data collection. The findings reveal that seven in ten of the factors exposed to respondents generated mean scores above 3.500, suggesting that the district is faced with many 'high degree' issues that impede the quality of healthcare at PHFs. Only two factors, namely 'community health education' $(\mu=3.454$; std. dev. $=1.088)$ and 'demographic dynamics' $(\mu=3.405$; std. dev. $=1.065)$, were rated with a moderate degree. In addition, one factor, 'a number of health workers at a facility', was rated low degree $(\mu=2.502$; std. dev. $=1.174)$.

\section{Enhancing the quality of healthcare in PHFs in Uganda}

Descriptive statistics were used to determine the means and standard deviations for each of the constructs under means for enhancing the quality of healthcare. The mean scores less than 2.500 were interpreted as 'low significance.' The mean scores ranging from 2.500 to 3.500 were interpreted as 'moderate significance,' and the mean scores above 3.500 were interpreted as 'high significance'.

Table 3. Descriptive statistics of means to enhancing the quality of healthcare

\begin{tabular}{llrr}
\hline No & Construct & Means & Std. dev. \\
1 & Reform the national health system & 4.279 & 0.894 \\
2 & Improve the overall working environment & 4.230 & 0.133 \\
3 & Increase national budgetary allocation & 4.211 & 0.880 \\
4 & Increased collaboration between health centres and hospitals & 3.114 & 0.964 \\
5 & Increased linkage between health workers' and patients' views on & 3.017 & 0.955 \\
& quality & 2.949 & 1.241 \\
6 & Increase community health education & 2.900 & 1.962 \\
7 & Increase duration and quality of industrial work experience & & \\
\hline
\end{tabular}




\begin{tabular}{llcc}
\hline 8 & Increased supervision of medical schools and or colleges & 3.842 & 1.908 \\
9 & Inclusion of demographic dynamics in health planning & 3.803 & 1.958 \\
10 & Increased number of health workers at a facility & 3.512 & 1.077 \\
& Average & $\mathbf{3 . 9 8 6}$ & $\mathbf{1 . 1 9 7}$ \\
\hline
\end{tabular}

Legend: less than 2.500 (less significance), 2.500 -3.500 (moderate significance), more than 3.500 (high significance)

Source: Primary data.

Table 3 above illustrates the different means for enhancing the quality of healthcare in PHFs in the Hoima district. The results indicate that six in ten of the constructs yielded 'high significant,' suggesting their degree of importance in raising the quality of healthcare. All the remaining four constructs yielded moderate significance, that is; increased collaboration between health centres and hospitals $(\mu=3114$; std. dev. $=0.964)$, increased linkage between health workers' and patients' views on quality $(\mu=3.017$; std. dev. $=0.955)$, increase community health education $(\mu=2.949$; std. dev. $=1.241)$, and increase duration and quality of industrial work experience undertaken by medical trainees $(\mu=2.900$; std. dev.=1962). The average scores generally indicated that all the constructs have high significance $(\mu=3.986$; std. dev. $=1.197)$ in enhancing the quality of healthcare in the Hoima district.

\section{Strategies by which LLGAs can enhance the quality of healthcare in PHFs}

According to a survey conducted by the researcher in the area of study, every health centre II and III is overseen by a health management committee appointed by the sub-county council. Consequently, any strategy to enhance the quality of healthcare in PHFs at this level falls directly on the sub-county council. Table 4 summaries the different strategies.

Table 4. Strategies by which LLGAs can enhance the quality of healthcare in PHFs

\begin{tabular}{lll}
\hline No & Strategy & Ranking \\
1 & Inclusion of two councillors on every HMC & 2 \\
2 & Regular monitoring of every PHF in their jurisdiction & 4 \\
3 & Joint planning between technical staff and council & 3 \\
4 & Improved communication channels between stakeholders & 4 \\
5 & Prioritising public health in every council session & 4 \\
\hline
\end{tabular}

Legend: 1=less important, 2=important, 3=fairly important, 4=very important

Source: Primary data.

Table 4 above presents the ranks for each of the five strategies that were identified during a pre-data collection survey conducted in the area of study. Results suggest that regular monitoring of every PHF in their jurisdiction, improved communication channels between stakeholders, and giving priority to public health in every council session are very important strategies for the LLGAs in their quest to enhance the quality of healthcare in PHFs. Joint planning between technical staff and council and inclusion of two councillors on every HMC are equally important but not as important as the first three constructs. These views attest to the fact that LLGAs have an essential role to play which can enhance the quality of healthcare in Hoima district and the entire nation where conditions are similar to those in the area of study.

\section{Discussion}

The major objective of this study was to determine means of enhancing the quality of healthcare in PHFs. In achieving this objective, four objectives were prioritised: (a) to determine the quality of healthcare among PHFs in Hoima district; (b) to determine the factors affecting the quality of healthcare in PHFs in Hoima district; (c) to determine the means by which the quality of healthcare in PHFs can be enhanced; And (d) to establish the strategies which LLGAs adopt to enhance the quality of healthcare in PHFs in Hoima district. The results of this study appear to agree with Brennan and Abimbola (2020) whose study showed that of all the factors affecting PHFs in Myanmar, not any is more insistent as the national health system $(\mu=4.366$; std. dev. $=0.39)$. Also, the results, in particular, the issue of inadequate resource envelope resonates what World health organisation (2016) observed that the African heads of state agreed, in 2001, to raise their annual budgetary allocation to at least $15 \%$ to health under the Abuja 
declaration. However, Uganda is yet to attain this as the government allocates $8.9 \%$ to the health sector, something that resonates with the PHFs (Aceng, 2021). This is largely a tributary of the entire health system, which has contributed to the countless challenges ranging from poor and or inadequate infrastructure, inadequate and obsolete medical equipment, and inadequate personnel to inadequate medicine. The findings from this study exposed that while a great proportion of respondents agreed that collaboration between health centres and hospitals is significant $(\mu=4.017$; std dev. $=0.855)$. These results agree with the observations put forth by other studies, which revealed that a number of PHFs lacked basic medicines, and where they exist, they are rarely adequate even for two weeks. For example, a survey conducted by Barton et al. (2019) in Uganda revealed issues of perception, fiscal, environmental, and caregiver limits to support recovery. In cases where the personnel fulfilled their duties, patients were only given prescriptions with no drugs. As a consequence, a number of patients end up at the drug shops, and for those who lack the financial ability to purchase drugs from drug shops and or pharmaceuticals, they resorted to local herbs.

\section{Implications of the study}

This study reveals that the four issues of effectiveness, safety, patient-centred and timeliness are very significant when assessing the quality of healthcare, especially in the developing nations as evidenced above. This mainly happens where facilities and the necessary resources to provide basic healthcare are available, but the delivery system is problematic in one way or another. This view continues to be noticed particularly in the less-developing nations where government allocation to labour (salaries and allowances) are not just low but delayed by the highly corrupt public systems. While there are remarkable signs of progress noted by the international agencies mainly the World Health Organisation (WHO), on average, across Eastern and central African countries, the quality of effectiveness, safety, patient-centred and timeliness in healthcare delivery is still wanting. The situation is even worse for much of the rural areas where timely restoking of vaccines and other basic supplies to health centre IIs and IIIs the aprish and the sub-counties respectively are both inadequate and never timely. This condition is even worsened by the ever inadequate staffing levels to cater to the growing demands of the ever-expanding population. By implication, the results from this study suggest that numerous interventions need to be taken up by the line ministries and departments along with every development partner in the health sector. For instance, reducing the rate of both infant mortality and maternal mortality is not enough unless the sector ensures that the same population will be taken off after five years and between pregnancies by enabling the health staff to deliver effective, safe, patient-centered, and timely service.

\section{Conclusion}

This study aimed to seek means of enhancing the quality of healthcare among PHFs in Hoima district, mid-western Uganda. From the findings, it is inferred that quality healthcare is a multifaceted concept; it is the ability of a PHF to provide timely and satisfying services needed to the client, and it is the responsibility of stakeholders to make sure that such services are provided. There is a need for every LLGA to design means of incorporating the dimensions of quality healthcare into their annual plans; every PHF should have a strong quality assurance unit that monitors issues of quality gaps and inform stakeholders to take corrective actions in time, and health personnel and patients should be encouraged to engage in the regular appraisal of the quality of health services delivered at a particular facility so as to deal with the undertones. Another dimension is the role of LLGAs in enhancing quality at PHFs; these entities have not been doing enough to ensure that the quality of healthcare in the district and beyond is enhanced. Hence, the need for the Ministry of Health, in close corroboration with Local Governments, must provide an enabling working environment by dealing decisively with the perennial issues that have been raised over time as well as the government of Uganda must ensure that it raises its budgetary allocation to the health sector to at least $12 \%$ in the medium-term given that the overall population is growing rapidly (punctuated by the influx of neighbouring communities from South Sudan, DRC, Somalia, and Rwanda. 


\section{Limitations and study forward}

This study only covers one district local government in a country where there are over 100 districts hence limiting the notion of generalization of results. Other studies may be conducted on assessing the quality of healthcare facilities, the workload of healthcare staff, and the adequacy of time allowed to the healthcare staff to rest, especially between night shifts.

\section{Acknowledgment}

The authors wish to appreciate every respondent who participated in the study.

\section{References}

Abiodun, A.J., and Adeyemi, K.S. (2020). Performance role models among public health facilities: an application of data envelopment analysis. International journal of healthcare management, 13(3):193-200. Doi: 10.1080/20479700.2017.1397379

Aceng, J.R. (2021). Health sector: Ministerial statement - financial year 2020/2021, MOH, Kampala.

Assaf, M. (2020). A new experience of online education under the COVID-19 pandemic for occupational therapy students in Palestine. World federation for occupational therapists bulletin, 76(2):103-7. Doi: 10.1080/14473828.2020.1825274

Bahendeka, S., Mutungi, G., Tugumisirize, F., Kamugisha, A., Nyangabyaki, C., Wesonga, R., Sseguya, W., Mubangizi, D., Nalunkuma, C., and Piloya, T. (2019). Healthcare delivery for paediatric and adolescent diabetes in low resource settings: type 1 diabetes clinics in Uganda. Global public health, 14(12):1869-83. Doi: 10.1080/17441692.2019.1611897

Barton, S.J., Sandhu, S., Doan, I., Blanchard, L., Dai, A., Paulenich, A., Smith, E.R., Van de Water, B.J., Martin, A.H., Seider, J., Namaganda, F., Opolot, S., Ekeji, N., Bility, M.M., and Bettger, J.P. (2019). Perceived barriers and supports to accessing community-based services for Uganda's paediatric post-surgical population. Disability and rehabilitation, doi: $10.1080 / 09638288.2019 .1694999$

Brennan, E., and Abimbola, S. (2020). Understanding and progressing health system decentralisation in Myanmar. Global security: health, science and policy, 5(1):17-27. Doi: $10.1080 / 23779497.2020 .1782247$

Cai, H., Zilm, F., Sheward, H., and Graham, K. (2020). Responding to COVID-19: healthcare surge capacity design for high-consequence infectious disease. Technology/architecture +design, 4(2):135-9. Doi: $10.1080 / 24751448.2020 .1804752$

Essue, B.M., and Kapiriri, L. (2020). Priority setting for health system strengthening in low income countries: a qualitative case study illustrating the complexities. Health systems, doi: $10.1080 / 20476965.2020 .1758596$

Fairchild, A., Gostin, L., and Bayer, R. (2020). Vexing, veiled, and inequitable: social distancing and the 'Rights' divide in the age of COVID-19. The American journal of bioethics, 20(7):55-61. Doi: $10.1080 / 15265161.2020 .1764142$

Gliem, J. A., \& Gliem, R. R. (2003). Calculating, interpreting, and reporting Cronbach's alpha reliability coefficient for Likert-type scales. Midwest Research-to-Practice Conference in Adult, Continuing, and Community Education.

Gomez-Degado, F., Katsiki, N., Lopez-Miranda, J., and Perez-Martinez, P. (2020). Dietary habits, lipoprotein metabolism and cardiovascular disease: from individual foods to dietary patterns. Critical reviews in food science and nutrition. Doi: 10.1080/10408398.2020.1764487

Imlawi, J., and Gregg, D. (2020). Understanding the satisfaction and continuance intention of knowledge contribution by health professionals in online health communities. Informants for health and social care, 45(2):151-67. Doi: 10.1080/17538157.2019.1625053

Jaja, I.F., Anyanwu, M.U., and Iwu Jaja, C. (2020). Social distancing: how religion, culture and burial ceremony undermine the effort to curb COVID-19 in South Africa. Emerging microbes \& infections, 9(1):1077-9. Doi: 10.1080/22221751.2020.1769501

Jaspal, R., Lopez, B., and Lopez, P. (2020). Predicting social distancing and compulsive buying behaviours in response to COVID-19 in a United Kingdom sample. Cogent psychology, 7(1). Doi: $10.1080 / 23311908.2020 .1800924$ 
Jayantkumar, P.H., and Dasharathbhai, P.N. (2019). Study on patient satisfaction of outpatient department in ESI hospitals at Ahmedabad, Vadodara, and Surat in state of Gujarat. International journal of healthcare management, 12(4):259-64. Doi: 10.1080/20479700.2017.1398441

Jillian, O., and Kizito, O. (2020). Socio-cultural factors associated with incomplete routine immunisation of children-Amach sub-county, Uganda. Cogent medicine, 7(1). Doi: 10.1080/2331205X.2020.1848755

Kwateng, K.O., Lumor, R., and Acheampong, F.O. (2019). Service quality in public and private hospitals: a comparative study on patient satisfaction. International journal of healthcare management, 12(4):251-8. Doi: 10.1080/20479700.2017.1390183

Leonce, T.E. (2020). A dynamic model of quality assurance in primary healthcare in developing countries. International journal of healthcare management. Doi: $10.1080 / 20479700.2020 .1756110$

Morais De Sousa, K., Pinhanez, M.M.S., Aguiar Do Monte, P., and Diniz, J.A. (2020). Salary, financial autonomy and efficiency of healthcare systems in local governments. Applied economics letters, 27(2):122-6. Doi: 10.1080/13504851.2019.1610697

Morgan, A.K. (2020). Making COVID-19 prevention etiquette of social distancing a reality for the homeless and slum dwellers in Ghana: lessons for consideration. Local environment, 25(7):53639. Doi: $10.1080 / 13549839.2020 .1789854$

$\mathrm{Mu}$, Y., Bossink, B., and Vinig, T. (2019). Service innovation quality in healthcare: service innovativeness and organisational renewal as driving forces. Total quality management \& business excellence, 30(11\&12):1219-34. Doi: $10.1080 / 14783363.2017 .1362954$

O’Donovan, J., Hamala, R., Namanda, A.S., Musoke, D., Ssemugabo, C., and Winters, N. (2020). 'We are the people whose opinions don't matter': a photo voice study exploring challenges faced by community health workers in Uganda. Global public health, 15(3):384-401. Doi: $\underline{10.1080 / 17441692.2019 .1663233}$

Okpala, P. (2020). Increasing access to quality healthcare through collaborative leadership. International journal of healthcare management, 13(3): 229-35. Doi: 10.1080/20479700.2017.1401276

Omona, K., and Namuli, W., (2020). Factors influencing utilisation of intra-uterine device among postpartum mothers at Gombe hospital, Butambala district, Uganda. Cogent medicine, 7(1). Doi: 10.1080/2331205X.2020.1846264

Rahman, S.Y. (2020). 'Social distancing' during COVID-19: the metaphors and politics of pandemic response in India. Health sociology review, 29(2):131-39. Doi: 10.1080/14461242.2020.1790404

Richter, J.P., and Kazley, A.S. (2020). Social media: How hospital Facebook activity may influence patient satisfaction. Health marketing quarterly, 37(1):1-9. Doi: 10.1080/07359683.2020.1713573

Ronca, E., Svheel-Sailer, A., Koch, H.G., Essig, S., Brah, M., Munzel, N., Gemperli, A., and swiSCI study group (2020). Satisfaction with access and quality of healthcare services for people with spinal cord injury living in the community. The journal of spinal cord medicine, 43(1):111-21. Doi: $10.1080 / 10790268.2018 .1486623$

Simmons, A.L. (2020). COVID-19 social distancing: A snippet view of the autistic social world. Disability \& society, 35(6):1007-11. Doi: 10.1080/09687599.2020.1774866

Suleri, J. (2020). Learners' experience and expectations during and post COVID-19 in higher education. Research in hospitality management, 10(2):91-9. Doi: 10.1080/22243534.2020.1869463

Thuy, H.T., Ha, D.T., Tuong, P.V., Thinh, C.Q., and Nga, N.T. (2020). Availability of essential medicines in primary healthcare in Vietnam. International journal of healthcare management. Doi: $10.1080 / 20479700.2020 .1756093$

Varea, V., and Gonzalez-Calvo, G. (2020). Touchless classes and absent bodies: teaching physical education in times of covid-19. Sport, education and society. Doi: $10.1080 / 13573322.2020 .1791814$

Walcott, R.L., Ingels, J.B., Corso, P.S., Zalwango, S., Whalen, C.C., and Sekandi, J.N. (2020). There's no such thing as a free TB diagnosis: catastrophic TB costs in urban Uganda. Global public health, 15(6): 877-88. Doi: 10.1080/17441692.2020.1724313 
Wasdani, K.P., and Prasad, A. (2020). The impossibility of social distancing among the urban poor: the case of an Indian slum in the times of COVID-19. Local environment, 25(5):414-8. Doi: $10.1080 / 13549839.2020 .1754375$

World health organisation. (2016). Public financing for health in Africa: from Abuja to the SDGs. Health financing toward UHC.

Wright, C. (2020). Local government fighting COVID-19. The round table, 109(3):338-9. Doi: $\underline{10.1080 / 00358533.2020 .1763017}$

Xie, X., Siau, K., and Nah, F.F. (2020). COVID-19 pandemic-online education in the new normal and the next normal. Journal of information technology case and application research, 22(3):17587. Doi: $10.1080 / 15228053.2020 .1824884$ 